Carlos Alarcón Cabrera

«DOS CONCEPTOS DE VALIDEZ» 


\title{
DOS CONCEPTOS DE VALIDEZ
}

\author{
Carlos Alarcón Cabrera \\ Universidad de Huelva
}

\section{Validez deóntica vs. validez dianoética}

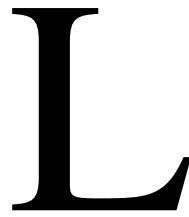

a posición del último Kelsen sobre la posibilidad de construir inferencias normativas parece clara: condición necesaria de validez de una norma es su existencia; condición necesaria de existencia de una norma es su producción mediante un acto de voluntad. A diferencia de las «descripciones», que son «sentidos de actos de pensamiento», y que como tales son verdaderas o falsas, las normas son «sentidos de actos de voluntad», y respecto a su validez (es decir, respecto a su existencia) no rigen principios lógicos como el de no contradicción o la regla de inferencia ${ }^{1}$.

Por ejemplo, la norma «Está prohibido a todos los vehículos circular por la izquierda» podría coexistir en un mismo ordenamiento con la norma «Está permitido a todos los vehículos circular por la izquierda» si también coexistieran dos actos de voluntad del legislador con los respectivos «sentidos». Asimismo, de la validez (de la existencia) de la norma «Está prohibido a todos los vehículos circular por la izquierda» no se infiere lógicamente la validez (la existencia) de la norma «Está prohibido a los vehículos de dos ruedas circular por la izquierda», validez que requiere un nuevo acto de voluntad.

Es más, el principio de no contradicción y la regla de inferencia no sólo no rigen respecto a la validez (como existencia) de las normas; tampoco son aplicables a las «proposiciones descriptivas» sobre la validez (como existencia) de las normas. Las proposiciones descriptivas «La norma "Está prohibido a todos los vehículos circular por la izquierda" es válida (existe)» y «La norma "Está permitido a todos los vehículos circular por la izquierda" es válida (existe)» no son contradictorias porque tienen objetos diferentes (tienen como objetos, respectivamente, la validez (la existencia) de cada una de las dos normas mencionadas). Asimismo, de la proposición descriptiva «La norma "Está prohibido a todos los vehículos circular por la

\footnotetext{
${ }^{1}$ Hans KELSEN, Recht und Logik, 1965; Allgemeine Theorie der Normen, 1979.
} 
izquierda" es válida (existe)» tampoco se infiere lógicamente la proposición descriptiva «La norma "Está prohibido a los vehículos de dos ruedas circular por la izquierda" es válida (existe)». La relación entre la norma general y la norma individual no es completa, para Kelsen, sin un nuevo acto de voluntad. Como este nuevo acto de voluntad puede no existir, ni la validez de la norma individual se infiere lógicamente de la validez de la norma general, ni una proposición descriptiva sobre la validez de la norma individual se infiere lógicamente de una proposición descriptiva sobre la validez de la norma general.

En palabras de Conte, In margine all'ultimo Kelsen, 1967, «a la validez [como existencia] de las proposiciones prescriptivas, la regla de inferencia no se aplica ni directamente, $n i$ indirectamente ${ }^{2}$ :

No se aplica directamente, porque para que una proposición prescriptiva individual sea válida (para que exista) no basta con que sea válida (con que exista) una proposición prescriptiva general de la que «parezca implicar». Condición necesaria de su validez (de su existencia) es su «posición» en el ordenamiento: debe estar «puesta» en el ordenamiento (por ejemplo, a través de una sentencia judicial) ${ }^{3}$.

No se aplica indirectamente, porque una proposición descriptiva que afirme la validez (como existencia) de una proposición prescriptiva individual no deriva lógicamente de una proposición descriptiva que afirme la validez (como existencia) de una proposición prescriptiva general. Condición necesaria de verdad de la primera proposición descriptiva no es la verdad de la segunda proposición descriptiva, sino la validez (la existencia) de la proposición prescriptiva individual; es decir, es necesario que la proposición prescriptiva individual haya sido «puesta» en el ordenamiento ${ }^{4}$.

Que la regla de inferencia no se aplique ni directamente ni indirectamente a la validez (como existencia) de las proposiciones prescriptivas no es, para Conte, paradójico, sino tautológico: «Sólo si una proposición prescriptiva existe, entonces existe; es irrelevante, para su existencia, que derive lógicamente de otra» ${ }^{5}$.

2 Amedeo G. Conte, In margine all'ultimo Kelsen, 1967, p. 116; Primi argomenti per una critica del normativismo, 1968, p. 10.

3 Amedeo G. Conte, In margine all'ultimo Kelsen, 1967, p. 116; Primi argomenti per una critica del normativismo, 1968, p. 10.

${ }^{4}$ Amedeo G. Conte, In margine all'ultimo Kelsen, 1967, p. 116-117; Primi argomenti per una critica del normativismo, 1968, p. 10.

5 Amedeo G. Conte, In margine all'ultimo Kelsen, 1967, p. 117-118; Primi argomenti per una critica del normativismo, 1968, p. 20-22. De hecho, como sugiere Conte, el principio de no contradicción y la regla de inferencia no sólo no rigen respecto a la existencia de las normas (respecto a la existencia de las «proposiciones prescriptivas in specie»); tampoco rigen respecto a la existencia de «ninguna cosa in genere». 
En otras palabras: la (supuesta) validez inferencial o «dianoética» («Gültigkeit») de una norma no es condición suficiente de su validez deóntica («Geltung»). La validez deóntica de una norma no depende de las normas (lógicas) de las que pueda depender que dicha norma sea «dianoéticamente» válida; depende de las reglas constitutivas del ordenamiento ${ }^{6}$. Aun aceptando que podamos inferir una norma de otra, ello no implica que podamos inferir la validez (deóntica) de la primera de la validez (deóntica) de la segunda.

\section{Constitutividad hipotética y validez}

Una tesis parcialmente contraria a la tesis de Kelsen (a la tesis según la cual la validez de una norma individual no deriva lógicamente de la validez de la norma general, sino que requiere un nuevo acto de voluntad cuyo sentido sea la norma individual; a la tesis según la cual la validez dianoética de una norma ${ }^{7}$ no es condición suficiente de su validez deóntica) ha sido defendida por Radice, Regole costitutive e sillogismo normativo, 1992. Según Radice, contra la tesis de Kelsen se puede oponer un «exemplum contrarium»: la validez deóntica de las reglas hipotético-constitutivas, de las reglas que ponen condiciones de aquello sobre lo que versan ${ }^{8}$, implica la validez deóntica de las conclusiones dianoéticamente válidas. No es necesario un nuevo acto de voluntad (por ejemplo, una sentencia judicial) para que la derivación individual de una regla hipotético-constitutiva sea deónticamente válida.

Siguiendo el ejemplo citado por Radice, de la regla hipotético-constitutiva «El interdicto tiene el domicilio del tutor» ${ }^{9}$, en conjunción con la premisa de hecho «Rossi es interdicto», deriva la conclusión normativa «Rossi tie-

${ }^{6}$ Cf. Amedeo G. Conte, Deontico vs dianoetico, 1986, pp. 490-491; Letizia Gianformaggio, Ancora su la logica e le norme, 1987; Tecla Mazzarese, Logica deontica e linguaggio giiuridico, 1989, pp. 101 ss.; Enrico Pattaro, Contributo al seminario «Se la logica si applichi alle norme», 1986; Carlos Alarcón Cabrera, En torno a la lógica deóntica del último Kelsen, 1989; Carlos Alarcón Cabrera, Normas y paradojas, 1993.

${ }^{7}$ Radice precisa que sólo metonímicamente se puede aludir a la «validez dianoética» de una norma. La norma es la conclusión de la «inferencia dianoéticamente válida» (Stefano A. Radice, Regole costitutive e sillogismo normativo, 1992, p. 422).

${ }^{8}$ Aunque Radice alude, como «exemplum contrarium» a la tesis de Kelsen, a las reglas hipotético-constitutivas, puede interpretarse que sólo se está refiriendo a una especie de regla hipotético-constitutiva: a las reglas metatético-constitutivas, a las reglas que ponen condiciones suficientes de aquello sobre lo que versan:

Por una parte, la premisa mayor del silogismo normativo que cita como ejemplo Radice es la regla metatético-constitutiva «El interdicto tiene el domicilio del tutor».

Por otra parte, cuando justifica el carácter (no constitutivo, sino) declarativo de una sentencia judicial aplicadora de una regla hipotético-constitutiva, Radice señala: «Si algo es, por ley, condición suficiente de un condicionado, y la condición suficiente se satisface, el juez no puede hacer otra cosa que declarar la subsistencia del condicionado» (Stefano A. Radice, Regole costitutive e sillogismo normativo, 1992, pp. 423-424).

${ }^{9}$ La norma «El interdicto tiene el domicilio del tutor» ha sido frecuentemente citada en el contexto teórico de las reglas constitutivas. 
ne el domicilio del tutor» ${ }^{10}$. La validez dianoética de «Rossi tiene el domicilio del tutor» es condición suficiente de su validez deóntica. Por la estructura de la regla hipotético-constitutiva, dice Radice, «la conclusión es, ipso iu$r e$, deónticamente válida en el ordenamiento en el que es deónticamente válida la premisa mayor El interdicto tiene el domicilio del tutor». Una sentencia judicial sobre el domicilio de un interdicto es declarativa y no constitutiva de validez deóntica: «la constitutividad de una regla hipotético-constitutiva excluye la constitutividad de la sentencia basada en tal regla» ${ }^{11}$.

\section{Dos conceptos ambiguos}

La tesis de Radice incita a formular una cuestión. Esta cuestión presupone la ambigüedad de dos conceptos.

La cuestión es la siguiente: ¿en qué sentido puede ser deónticamente válida una norma inferida de otra norma deónticamente válida?

Los conceptos cuya ambigüedad se presupone al formular esta cuestión son los conceptos de «norma» y de «validez deóntica».

\section{1. «Status deóntico»vs. «enunciado deóntico»; «validez sintáctica»vs. «validez semántica»}

Para hacer frente a la mencionada ambigüedad, Conte distinguió (Studio per una teoria della validità, 1970) entre «norma» como «enunciado deón-

En Regola costitutiva, condizione, antinomia, 1983, Conte afirma que esta norma pertenece al conjunto de las reglas «thético-constitutivas», reglas que, como «actos performatios théticos» (actos que son una «thésis», que son una posición de verdad), son condición suficiente de aquello sobre lo que versan, «constituyen estados de cosas théticos subsistentes en el ordenamiento y por el ordenamiento en el que son válidas», no prescriben que un agente ponga un estado de cosas, sino que lo ponen ellas mismas: «La norma El interdicto tiene el domicilio del tutor, a diferencia de la regla que prescribe al profesor la residencia en la sede de su universidad, [...] adscribe al interdicto el domicilio del tutor (Amedeo G. Conte, Regola costitutiva, condizione, antinomia, 1983, p. 25 y nota 8. Cf. Amedeo G. Conte, Aspetti della semantica del linguaggio deontico, 1977, pp. 154-162; Giampaolo M. Azzoni, Il concetto di condizione nella tipologia delle regole, 1988 , p. 57).

En Norme che sono condizioni sufficienti del loro oggetto?, 1986, Guastini indica que tanto si la norma «El interdicto tiene el domicilio del tutor» se reestructura sintácticamente siguiendo el modelo «si $f$, entonces $g »$ ( «Si una persona es interdicta, entonces tiene el domicilio de su tutor»), como si se reestructura sintácticamente siguiendo el modelo «x» tiene valor de «y» («El domicilio del tutor tiene valor de domicilio del interdicto»), esta norma no es condición suficiente de aquello sobre lo que versa, no es condición suficiente de su objeto (en el primer caso no es condición suficiente del hecho de la interdicción, en el segundo caso no es condición suficiente del domicilio del tutor). La norma «El interdicto tiene el domicilio del tutor» es condición suficiente (no de su objeto, sino) de su efecto, es condición suficiente de la adquisición del domicilio del tutor por parte del interdicto, por lo que sólo impropiamente puede considerarse una regla thético-constitutiva (Riccardo Guastini, Norme che sono condizioni sufficienti del loro oggetto?, 1986, pp. 218-221).

${ }^{10}$ Stefano A. Radice, Regole costitutive e sillogismo normativo, 1992, pp. 423-424.

${ }^{11}$ Stefano A. Radice, Regole costitutive e sillogismo normativo, 1992, p. 424. 
tico», como enunciado que sigue el modelo «el comportamiento $\mathrm{C}$ es $\mathrm{D}$ » (donde D designa un modo deóntico: obligatorio, prohibido, permitido...) y «norma» como «status deóntico», como estado de cosas extralingüístico sobre el que versa un enunciado deóntico (una obligación, una prohibición, una permisión...) ${ }^{12}$.

Paralelo al paradigma «enunciado deóntico» vs. «status deóntico» es otro paradigma: el paradigma «validez deóntica semántica» vs. «validez deóntica sintáctica». La validez sintáctica, predicable de las normas como status deónticos, es relativa a las reglas constitutivas que «en» $\mathrm{y}$ «por» un ordenamiento definen la validez, a las reglas que determinan la «sintaxis de validez»; en particular, es relativa a la norma fundamental del ordenamiento ${ }^{13}$. La validez semántica, predicable de las normas como enunciados deónticos, es relativa a la correspondencia de un enunciado deóntico con un status deóntico. La validez semántica de los enunciados deónticos es el valor correlativo a la verdad de los enunciados apofánticos: los enunciados deónticos son semánticamente válidos o semánticamente inválidos de forma análoga a cómo los enunciados apofánticos son verdaderos o falsos ${ }^{14}$.

La validez sintáctica de un status deóntico constituido en un ordenamiento y por un ordenamiento es condición suficiente de validez semántica $\left(\right.$ «thética» ${ }^{15}$ ) del enunciado deóntico correspondiente. El enunciado deóntico «Está prohibido a todos los vehículos circular por la izquierda» es semánticamente válido si es verdad (en un ordenamiento y por un ordenamiento) que está prohibido a todos los vehículos circular por la izquierda; es decir, si en un ordenamiento y por un ordenamiento es sintácticamente

12 Amedeo G. Conte, Studi per una teoria della validità, 1970, pp. 334-342.

13 Amedeo G. Conte, Minima deontica, 1988, pp. 435-437 y 454-461.

${ }_{14}$ Amedeo G. Conte, Minima deontica, 1988, p. 446-448.

${ }^{15}$ Cf. Amedeo G. Conte, Minima deontica, p. 448. Al afirmar que la validez sintáctica de un status deóntico constituido «en» un ordenamiento y «por» un ordenamiento es condición suficiente de validez semántica del enunciado deóntico correspondiente asumo implícitamente como hipótesis que toda validez semántica es validez semántica «thética».

Los conceptos de «validez semántica thética» y de «validez semántica athética» reproducen en términos novedosos la clásica polémica doctrinal que enfrenta al positivismo jurídico y al iusnaturalismo: La validez semántica thética de un enunciado deóntico depende de su correspondencia con un status deóntico («théticamente») constituido en un ordenamiento y por un ordenamiento. La validez semántica athética de un enunciado deóntico depende de su correspondencia, en palabras de Kalinowski, con la «realidad deóntica» (el enunciado deóntico «Está prohibido el incesto» posee validez semántica athética si, conforme a la realidad deóntica, está prohibido el incesto, y aunque «en» y «por» un ordenamiento no sea verdad que está prohibido el incesto: es decir, aunque el status deóntico «Está prohibido el incesto», no posea, «en» $\mathrm{y}$ «por» un ordenamiento, validez sintáctica). Para Azzoni, el concepto de validez semántica athética como verdad deóntica athética se define, a la luz de la obra de Kalinowski, mediante dos tesis: (i) las normas designan estados de cosas normativos (tesis de la designatividad de las normas), (ii) las normas pueden ser verdaderas o falsas (tesis de la apofanticidad de 
válido el status deóntico «Está prohibido a todos los vehículos circular por la izquierda».

\subsection{El origen del concepto de validez semántica}

\subsubsection{Validez como verdad}

La expresión «validez semántica» es, sin embargo, en Conte, posterior al concepto de «validez semántica». En In margine all'ultimo Kelsen, 1967, Conte no sólo analizó cómo el principio de no contradicción y la regla de inferencia no son aplicables a la validez de las «proposiciones prescriptivas» entendida como existencia (utilizando la expresión posterior, a la validez (sintáctica) de las normas como status deónticos). También se refirió a la aplicabilidad de ambos principios lógicos a la validez de las «proposiciones prescriptivas» entendida como verdad (utilizando la expresión posterior, a la validez (semántica) de las normas como enunciados deónticos) partiendo de la siguiente hipótesis: «Las proposiciones prescriptivas pueden ser o verdaderas, o falsas, ya que son o verdaderas, o falsas ( $a b$ esse ad posse valet consequentia); son o verdaderas, o falsas, ya que son verdaderas (una disyunción es verdadera si es verdadero uno de sus términos); son verdaderas porque son necesariamente verdaderas» ${ }^{16}$.

En este sentido, los enunciados deónticos serían verdaderos o falsos según se correspondieran o no con su objeto. Del mismo modo que el enunciado adeóntico «Juan fuma» es verdadero si se corresponde con su objeto (si Juan fuma) o es falso si no se corresponde con su objeto (si Juan no fuma), el enunciado deóntico «Está prohibido fumar» podría considerarse verdadero (válido en tanto que verdadero) si se corresponde con su objeto [si está prohibido fumar, si el status deóntico «Está prohibido fumar» es (sintácticamente) válido en tanto que existe], o podría considerarse falso (inválido en tanto que falso) si no se corresponde con su objeto [si no está prohibido fumar, si el status deóntico «Está prohibido fumar» no es (sintácticamente) válido en tanto que no existe]. De la misma forma que la proposición descriptiva expresada por el enunciado «Juan fuma» no es lo mismo que el hecho de que Juan fume, la proposición prescriptiva expresada por el enunciado «Está prohibido fumar» no es lo mismo que el hecho de la prohibición de fumar ${ }^{17}$.

las normas) (Giampaolo M. Azzoni, Validità semantica in deontica, 1992, pp. 171 ss.; Georges Kalinowski, Le problème de la vérité en morale et en droit, 1967).

${ }^{16}$ Amedeo G. Conte, In margine all'ultimo Kelsen, 1967, p. 120; Primi argomenti per una critica del normativismo, 1968, p. 24.

${ }^{17}$ Amedeo G. Conte, In margine all'ultimo Kelsen, 1967, pp. 119-120; Primi argomenti per una critica del normativismo, 1968, pp. 23-24. Cf. Juan R. Capella Hernández, El derecho como lenguaje, 1968, pp. 88-104; Carlos E. Alchourrón y Eugenio Bulygin, Verdad deóntica 


\subsubsection{Validez como condición de verdad}

En una línea similar, en Aspetti della semantica del linguaggio deontico, $1977^{18}$, Conte rechazó la incompatibilidad entre verdad y performatividad utilizando la distinción entre «enunciado» («Satz», «sentence») y «enunciación» («Ausserung», «utterance») de un enunciado. Que la enunciación performativa de un enunciado no sea ni verdadera ni falsa, sino válida o inválida, no significa que el enunciado que se enuncia performativamente no pueda ser verdadero ni falso. Al contrario, recalca Conte, un enunciado performativo es verdadero precisamente en tanto que se usa performativamente, en tanto que quien lo enuncia, al enunciarlo performativamente, hace lo que dice: «la performatividad de la enunciación es condición necesaria y suficiente de verdad del enunciado» ${ }^{19}$.

\section{De la paradigmática de la validez a la sintagmática de la validez}

En el epígrafe 1. me he referido al concepto kelseniano de validez como existencia y a sus efectos sobre la imposibilidad de inferir la validez de una norma individual de la validez de una norma general.

En el epígrafe 2., me he referido a la tesis según la cual caben excepciones a la tesis descrita en 1.; en concreto, en 2., me he referido a la tesis según la

y valores, 1983; Dora Sánchez García, Definición de la norma verdadera, 1986, pp. 18 ss.; Carlos Alchourrón y Antonio A. Martino, Lógica sin verdad, 1988, pp. 18 ss.; sobre el concepto semántico de validez en von Wright: Georg H. von Wright, Norm and Action, 1963, pp. 140 y 196; Paolo di Lucia, Deontica in von Wright, 1992, pp. 67-74.

18 Amedeo G. Conte, Aspetti della semantica del linguaggio deontico, 1977 (edición alemana: Aspekte der Semantik der deontischen Sprache, 1977). Intermedios entre In margine all'ultimo Kelsen, 1967, y Aspetti della semantica del linguaggio deontico, 1977, son destacables otros dos ensayos sobre el origen del concepto de validez semántica: Amedeo G. Conte, Ricerca d'un paradosso deontico, 1974; Amedeo G. Conte, Experimente mit der Fachsprache der Deontik. Kritisches zur Sprache der Semantik der normativen Sprache, 1975, (Cf. Carlos Alarcón Cabrera, Nuevos materiales para una semántica del lenguaje normativo. Lecturas deónticas de una paradoja de Lewis Carroll, 1994).

19 Amedeo G. Conte, Aspetti della semantica del linguaggio deontico, 1977, pp. 150-151 (Cf. Maria-Elisabeth Conte, La pragmatica linguistica, 1983, pp. 98-107; Maria-Elisabeth Conte, Délocutivité, Performativité, Contreperformativité, 1984; Andrea Rossetti, Performativi in Jean-Louis Gardies: verità, verificabilità, vero-funzionalità, 1994). Como señala Conte, el enunciado «Abdico» de un rey que abdica sin cumplir algún requisito legal no es falso, sino que la enunciación del enunciado es inválida.

El hecho de que la performatividad no sólo no excluya, sino que incluya necesariamente la verdad del enunciado, explica la crítica de Radice a la consideración de las reglas hipotético-constitutivas como enunciados declarativos apofánticos (argumento con el que, precisamente, Kelsen justificó el carácter teórico y no normativo de los silogismos construidos a partir de reglas hipotético-constitutivas): «[...] si el art. 457 del Código civil suizo ["Los herederos son los descendientes del difunto"] es realmente (como Kelsen afirma) un enunciado declarativo apofántico, o sea, susceptible de verdad y de falsedad ( "wahr oder unwahr”), ¿en qué condiciones se predicaría de él la falsedad (la "Unwahrheit”)?» (Stefano A. Radice, Regole costitutive e sillogismo normativo, 1992, pp. 425-427). 
cual de la validez (deóntica) de una determinada especie de normas generales (las reglas hipotético-constitutivas) sí se infiere la validez (deóntica) de las correspondientes normas individuales (por lo que las correspondientes sentencias judiciales no serían constitutivas de validez, sino declarativas de validez).

En el epígrafe 3. he procurado profundizar en el concepto de «validez semántica» de los enunciados deónticos (validez no como existencia, sino como verdad), delimitándolo del concepto de «validez sintáctica» de los status deónticos (validez como existencia).

Queda así abierto el camino para responder a la cuestión con la que iniciaba 3.: ¿En qué sentido es deónticamente válida una norma inferida de otra norma deónticamente válida?

Esta cuestión puede ser reformulada centrándose en el ejemplo de regla hipotético-constitutiva citado por Radice: si es deónticamente válida la norma general «El interdicto tiene el domicilio del tutor», ¿en qué sentido es deónticamente válida la norma individual «Rossi tiene el domicilio del tutor»?

De la validez sintáctica de un status deóntico general no se infiere la validez sintáctica de un status deóntico individual: la validez sintáctica del status deóntico «El interdicto tiene el domicilio del tutor» no es condición suficiente de validez sintáctica del status deóntico «Rossi tiene el domicilio del tutor». Aunque, «en» y «por» un ordenamiento, exista (sea válido en tanto que existente) el status deóntico «El interdicto tiene el domicilio del tutor», puede no existir (puede no ser válido en tanto que no existente) el status deóntico «Rossi tiene el domicilio del tutor»; condición necesaria de su existencia (de su validez como existencia) es un nuevo acto de voluntad que lo produzca ${ }^{20}$.

De la validez semántica de un enunciado deóntico general sí se infiere la validez semántica de un enunciado deóntico individual: la validez semántica del enunciado deóntico «El interdicto tiene el domicilio del tutor» sí es condición suficiente de validez semántica del enunciado deóntico «Rossi tiene el domicilio del tutor». Si es verdad (si es válido en tanto que verdadero) que, «en»y «por» un ordenamiento, el interdicto tiene el domicilio del tutor, entonces es verdad (es válido en tanto que verdadero) que Rossi tiene el domicilio del tutor.

${ }^{20}$ De hecho, siguiendo los conceptos kelsenianos de validez como «existencia» y de norma como «sentido de un acto de voluntad», la regla hipotético-constitutiva «El interdicto tiene el domicilio del tutor» podría coexistir en un mismo ordenamiento con la regla hipotéticoconstitutiva «El interdicto tiene el domicilio del pariente más próximo» si también coexistieran dos actos de voluntad del legislador con los respectivos «sentidos». Una sentencia judicial que «adscribiera» al interdicto el domicilio del tutor sería constitutiva y no meramente declarativa (la constitutividad de la regla hipotético-constitutiva «El interdicto tiene el domicilio del tutor» no excluye la constitutividad de la sentencia judicial «Rossi tiene el domicilio del tutor») (Cf. Stefano Radice, Regole costitutive e sillogismo normativo, 1992, pp. 424-427). 
Independientemente de su naturaleza, la validez sintáctica de la norma general (del status deóntico general) no es condición suficiente de validez sintáctica de la norma individual (del status deóntico individual), pero la validez semántica de la norma general (del enunciado deóntico general) sí es condición suficiente de validez semántica de la norma individual (del enunciado deóntico individual). Las relaciones condicionales no son distintas, en contra de lo afirmado por Radice, si se trata de reglas hipotético-constitutivas y no de reglas regulativas:

(i) También la validez semántica del enunciado deóntico regulativo «Está prohibido a todos los vehículos circular por la izquierda» es condición suficiente de validez semántica del enunciado deóntico «Está prohibido a los vehículos de dos ruedas circular por la izquierda» (porque si es verdad -si es válido en tanto que verdadero-, «en» y «por» un ordenamiento, que está prohibido a todos los vehículos circular por la izquierda, entonces es verdad -es válido en tanto que verdadero- que está prohibido a los vehículos de dos ruedas circular por la izquierda).

(ii) Tampoco la validez sintáctica del status deontico regulativo «Está prohibido a todos los vehículos circular por la izquierda» es condición suficiente de validez sintáctica del status deóntico «Está prohibido a los vehículos de dos ruedas circular por la izquierda» (porque aunque exista -aunque sea válido en tanto que existente-, «en» y «por» un ordenamiento, el status deóntico «Está prohibido a todos los vehículos circular por la izquierda», puede no existir -no ser válido en tanto que no existente- el status deóntico «Está prohibido a los vehículos de dos ruedas circular por la izquierda»).

En definitiva, Radice resuelve la cuestión de si es posible derivar la validez deóntica de una norma individual de la validez deóntica de una norma general atendiendo al carácter hipotético-constitutivo o al carácter regulativo de la norma general. En mi opinión, la cuestión habría que plantearla en términos de «relación condicional asimétrica» entre los conceptos de «validez sintáctica» $\mathrm{y}$ «validez semántica»:

(i) La validez sintáctica de un status deóntico general no es condición suficiente de validez sintáctica de los status deónticos individuales; la validez semántica de un enunciado deóntico general sí es condición suficiente de validez semántica de los enunciados deónticos individuales.

(ii) La validez sintáctica de un status deóntico sí es condición suficiente de validez semántica del enunciado deóntico correspondiente al status deóntico; la validez semántica de un enunciado deóntico no es condición suficiente de validez sintáctica del status deóntico al que corresponde el enunciado deóntico (un enunciado deóntico individual puede ser semánticamente válido 
sin que el status deóntico individual al que corresponde sea sintácticamente válido).

Ya Conte, en In margine all'ultimo Kelsen, 1967, y en Primi argomenti per una critica del normativismo, 1968, había apuntado que al reinterpretar el problema de la aplicabilidad de la regla de inferencia a la validez de las «proposiciones prescriptivas», en el sentido de validez como verdad (utilizando la expresión posterior: como validez semántica de los enunciados deónticos), y no en el sentido kelseniano de validez como existencia (utilizando la expresión posterior: como validez sintáctica de los status deónticos), dicho problema tiene una solución distinta, porque si «una proposición prescriptiva» general es válida en el sentido de verdadero (si un enunciado deóntico general es semánticamente válido), entonces cada una de las «proposiciones descriptivas» individuales que implica la «proposición prescriptiva» general son válidas en el sentido de verdaderas (cada uno de los enunciados deónticos individuales son semánticamente válidos). Pero si nos atenemos al concepto de validez como existencia (al concepto de validez sintáctica de los status deónticos), la validez de la «proposición prescriptiva» general no implica la validez de la «proposición prescriptiva» individual (la validez sintáctica del status deóntico general no implica la validez sintáctica del status deóntico individual); es necesario que tal validez sea «puesta» por un acto de voluntad normativo. «La razón de ello no es una determinada propiedad de las dos proposiciones prescriptivas (su prescriptividad), sino la relación [dinámica] que existe entre las dos proposiciones prescriptivas» ${ }^{21}$.

${ }^{21}$ Amedeo G. CONTE, In margine all'ultimo Kelsen, 1967, pp. 207-208; Primi argomenti per una critica del normativismo, 1968, pp. 38-39.

\section{DOXA 22 (1999)}

